\title{
Cidade para Viver ou Trabalhar? Contradições da Distribuição de Atividades, Transporte e Condições Sociais: Estudo de Caso da Cidade do Rio de Janeiro
}

\author{
A City to Live or Work In? Contradictions Present in the \\ Spatial Distribution of Economic Activities, Transport and \\ Social Conditions: A Case Study of the City of Rio de Janeiro
}

\author{
Vicente Aprigliano Fernandes ${ }^{i}$ \\ Pontificia Universidad Católica de Chile \\ Santiago, Chile \\ Cristián Henríquezii \\ Pontificia Universidad Católica de Chile \\ Santiago, Chile \\ Cesar Leal Soto ${ }^{\mathrm{iii}}$ \\ Univesity of Tuebingen \\ Tuebingen, Alemanha
}

Resumo: Apesar de existir, atualmente, um esforço do setor de transportes do Rio de Janeiro para demonstrar as contribuições das recentes soluções de mobilidade urbana para as questões sociais, ambientais e econômicas, ainda parece contraditório, quando a cidade em reestruturação continua apresentando uma distribuição desigual dos postos de trabalho, alto índice de desigualdade social e problemas crônicos de mobilidade urbana, como alto índice de uso de transporte privado, baixo nível de serviço do transporte público, longos trajetos e tempos de viagens. Esta contribuição busca avaliar a relação da infraestrutura de transportes disponíveis com a dinâmica de empregos e empresas da cidade do Rio de Janeiro, sob uma perspectiva geográfica. Com as análises geradas, será possível observar se os meios de transportes existentes e projetados para a cidade estão reproduzindo interesses já estabelecidos no curso da história, ou buscam gerar rupturas e novas logicas espaciais, com a intenção de reduzir as diferenças socioespaciais.

Palavras-chave: Distribuição de Atividades; Transporte; Segregação Socioespacial.

\footnotetext{
' Departamento de Ingeniería de Transporte y Logística/Centro de Desarrollo Urbano Sustentable (CEDEUS). vicente.fernandes@uc.cl

ii Instituto de Geografía/Centro de Desarrollo Urbano Sustentable (CEDEUS).

iii Instituto de Geografia.
} 
Abstract: Although there is currently an effort by the transport sector of Rio de Janeiro to demonstrate the contribution of urban mobility for addressing social, environmental and economic issues, the claims are contradictory because urban restructuring continues to cause the uneven distribution of jobs in the city, high levels of social inequality and chronic problems with poor urban mobility, as seen in high levels of private transportation use, low levels of public transport service, long journeys and travel times. This work uses a geographical perspective to evaluate the relationship between available transport infrastructure and the dynamics of jobs and businesses in the city of Rio de Janeiro. We seek to evaluate whether the existing and projected means of transportation in the city merely attend to the demands of historically established interest groups or create ruptures and new spatial logics which reduce socio-spatial differences.

Keywords: Distribution of Activities; Transport; Socio-Spatial Segregation.

\section{Introdução}

A cidade do Rio de Janeiro vem produzindo e reproduzindo uma lógica de intensificação da desigualdade social. Esta lógica é um reflexo das oportunidades oferecidas pela cidade e de como elas estão distribuídas no espaço urbano, envolvendo acesso a saúde, educação, serviços, áreas de lazer etc. Se o acesso aos serviços básicos, às áreas de lazer e aos locais de trabalho não estiverem a uma distância aceitável para ser percorrido a pé, isso significa que existe a necessidade de implementar tecnologias de encolhimento do espaço (space-shrinking technologies), conhecidos também como sistemas de transporte e telecomunicação, com a intenção de permitir o acesso aos serviços apontados anteriormente e aos locais de trabalho.

Entretanto, existe uma complexidade na implementação de um sistema de transporte adequado no meio urbano, pelos diversos fatores envolvidos neste processo, alguns dos quais considera a demanda a ser atendida, custo de implementação e operação, tempo de realização do projeto, entre outros. Apesar de existir atualmente um esforço do setor de transportes do Rio de Janeiro de demonstrar as contribuições das recentes soluções de mobilidade urbana para as questões sociais, ambientais e econômicas, ainda parece contraditório, quando a cidade continua apresentando uma distribuição desigual dos postos de trabalho na cidade, alto índice de desigualdade social e problemas crônicos de mobilidade urbana, como alto índice de uso de transporte privado, baixo nível de serviço do transporte público, longos trajetos e tempos de viagens.

Sob a perspectiva da geografia econômica, com a evolução dos sistemas de produção (exemplo, fordismo, pós-fordismo, sistema flexível de produção), é argumentado que, no contexto urbano atual, existe a tendência de se adotar uma estratégia de economias de aglomeração, com a intenção de aglomerar atividades urbanas que se beneficiem da mesma infraestrutura urbana, por exemplo, o sistema de transporte. Desta forma, deve-se esperar que a concentração de infraestrutura de transporte tenha uma relação estrita com a concentração de serviços e consequentemente de empregos. Sob a perspectiva da reestru- 
turação urbana, busca-se compreender as ações que geram uma ruptura e mudanças nos aspectos relacionados a funcionalidade e uso da cidade, no espaço e no tempo.

Este artigo tem o objetivo de caracterizar os espaços para viver e trabalhar, em função do acesso a meios de transporte público, viagens originadas/destinadas, da distribuição de empregos e empresas, e em função da renda dos habitantes e empregados na cidade do Rio de Janeiro, sob uma perspectiva geográfica. Com a compreensão das tendências da cidade do Rio de Janeiro no espaço e no tempo, e as análises geradas neste artigo, será possível observar se os meios de transportes existentes e projetados para a cidade estão reproduzindo interesses já estabelecidos no curso da história, ou buscam gerar rupturas e novas lógicas espaciais, com a intenção de reduzir as disparidades socioespaciais.

\section{Mobilidade Urbana e Produção do Espaço Urbano}

Urbanização, crescimento populacional, desenvolvimento econômico, mobilidade social e conflitos urbanos são tópicos que motivaram um aumento significativos dos trabalhos científicos voltados para estudos urbanos. E os estudos urbanos sob uma perspectiva social ganharam visibilidade no século XX, através da Escola de Chicago (Scott \& Storper, 2014; Castells, 2002; May \& Perry, 2005).

Desde então, pode-se dizer que existem quatro temas que se destacaram dentro dos estudos urbanos: produção do espaço (Castells, 2009; Carlos, et al., 2011; Lefebvre, 2008; Soja, et al., 1983; Lefebvre, 1991; Molotch, 1993); direito a cidade (Harvey, 2003; Lefebvre, 1995; Harvey, 2012); consumo coletivo (Castells, 2002; 1983; Walton, 1993); movimentos sociais (Castells, 1983; Harvey, 2012).

Estes quatro temas são dificilmente separáveis, para qualquer estudo que tenha preocupação de compreender o espaço urbano, suas contradições e tendências. Com relação a produção do espaço, Castells (2009) defende que a organização social do espaço pode ser compreendido pelas expressões geográficas dos aspectos econômicos, político-institucional e as origens ou natureza das contradições urbanas. De forma mais concreta, estas expressões espaciais podem ser um reflexo dos seguintes processos urbanos: (1) concentração; (2) centralização; (3) descentralização: (4) circulação; (5) segregação; e (6) invasão-sucessão (invasion-succession).

Estes processos envolvem (Castells, 2009): a densidade demográfica (1); especialização funcional das atividades dentro da rede urbana (2 e 3); circulação de pessoas, bens e informações (4); diferenciação das condições sociais entre unidades dentro espaço (5); e o processo de inserção de uma população ou atividades em um espaço já ocupado, onde o novo pode ser rejeitado, entretanto se mantendo como atividade ou população dominante (6).

Com relação ao direito à cidade, Harvey (2008) aponta que as cidade são moldadas por uma necessidade continua de encontrar formas espaciais de gerem maior produção e absorção do excedente de capital. Ou seja, existem agentes da produção do espaço urbano que são dominantes (exemplo, grandes empresários, políticos, classes sociais com maior renda etc.), e possuem maior influência na determinação das funções do espaço urbano, gerando a exclusão e acentuando a vulnerabilidade de outros agentes 
menos influentes neste processo (exemplo, pequenos empresários, classes sociais com menor renda etc.).

A questão dos movimentos sociais está associada com o tema de consumo coletivo (Castells, 1983), pois as formas urbanas são determinadas por seus significados (urban meaning). O significado urbano pode ser definido como o processo histórico e conflituoso entre os agentes responsáveis pela produção e construção do espaço urbano. Este processo histórico da produção do espaço urbano define as funções e formas urbanas (Capel, 2016).

Para complementar esta discussão, é importante destacar o papel do sistema de transporte e mobilidade no contexto de produção do espaço urbano. Com enfoque na perspectiva sociológica do transporte, é relevante compreender os motivos pelos quais algumas pessoas ou setores da cidade possuem mais ou menos acesso a determinados sistemas de transporte (Vasconcellos, 2014). Estes motivos podem estar relacionados com condições socioespaciais e com o nível de influência dos diferentes agentes de produção do espaço urbano na construção de espaços mais acessíveis em termos de transporte e mobilidade.

Para aproximar mais o tema de mobilidade e transporte na produção do espaço urbano, é necessário contextualizar suas características com os temas de estudos urbanos apontados anteriormente. Primeiramente, pode-se definir que o sistema de transporte é um serviço de consumo coletivo. A forma que este sistema está distribuído na cidade pode ser um reflexo das contradições urbanas, e levando a cidade a potencializar lógicas de produção e acumulação de capital. Nesta lógica, a concentração deste serviço pode estar relacionado com os níveis de salários nas diferentes partes da cidade, assim, contradizendo o seus significado de consumo coletivo (Castells, 1983).

Desta forma, o sistema de transporte pode limitar o acesso de classes sociais de baixa renda a áreas da cidade que possuem um significado e funções associadas a classes de alta renda. No caso brasileiro, a limitação da circulação e locomoção de cidadãos dentro de seu território infringe o Art. 5, inc. XV da Constituição Federal de 1988, em que se defende o direito de ir e vir, garantindo direito à vida, à liberdade, à igualdade, à segurança e à propriedade. Estes direitos estão intimamente relacionados com o tema de direito a cidade, que consiste não apenas na igualdade de acesso as atividades e serviços oferecidos, mas também envolve o direito de participar e de se beneficiar do processo de produção do espaço urbano (Harvey, 2008).

Para entender a relação reciproca entre transporte e espaço urbano, apresentam-se aqui as Figuras 1, 2 e 3, que ajudam a ilustrar esta relação e como ela se insere no processo de produção do espaço urbano.

A Figura 1 demonstra que uma viagem, para ser realizada, depende das necessidades de um indivíduo, o sistema de transporte disponível e os recursos financeiros e humanos (em termos de nível de educação). Estes três componentes podem levar a viagens possíveis ou adaptadas para a realização da atividade de interesse, ou podem levar um indivíduo a confrontar a possibilidade de uma viagem impossível, levando o indivíduo a ter de buscar alternativas, adaptar a viagem ou ter sua viagem e realização da atividade de interesse suprimida. A viagem suprimida é um reflexo das deficiências das condições de mobilidade, podendo levar a uma pressão sobre o indivíduo e a necessidade de exigir melhoras das condições de mobilidade através de movimentos sociais. 


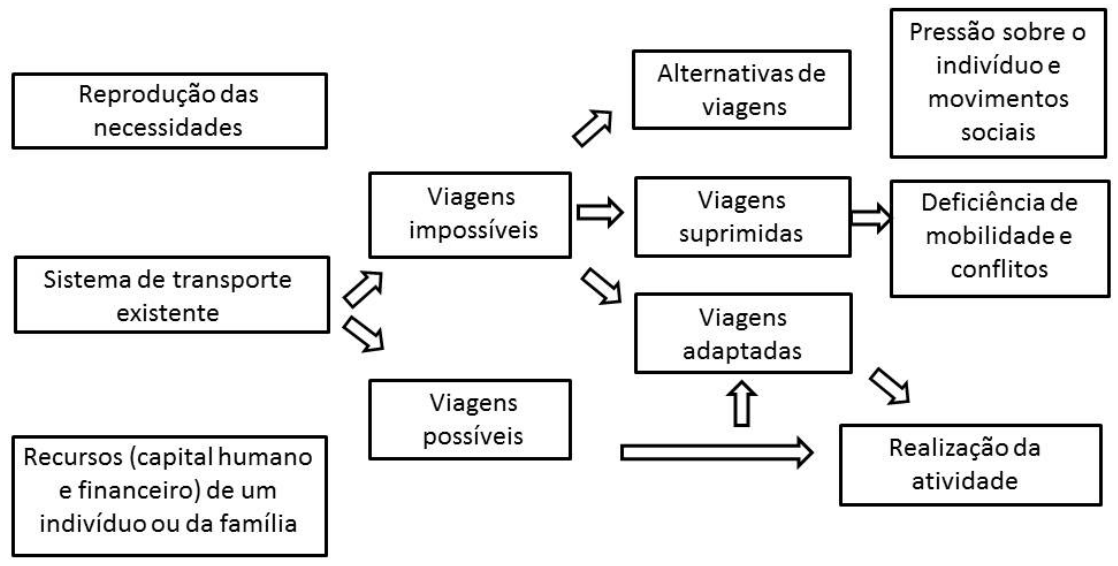

Figura 1 - Condições determinantes para realização de atividades que dependem ou não de um meio de transporte.

Adaptado de: Vasconcellos (2014).

A Figura 2 demonstra que a necessidade de um indivíduo está relacionada com a divisão social do trabalho (função dentro da sociedade), divisão técnica do trabalho (nível de qualificação), classe social, etnia, religião, idade, gênero, e experiência de vida. Esta reprodução de necessidades e suas condicionantes estão intimamente ligadas à relação de um indivíduo com o espaço. Esta relação pode-se definir como nível de atratividade de uma pessoa com um certo lugar. Ou seja, se a necessidade de uma pessoa é compatível com os serviços oferecidos em um lugar, isto significa que existe um certo nível de atratividade. Esta atratividade pode gerar uma alternativa para a realização de atividades em um contexto de viagem impossível, como mostra a Figura 3.

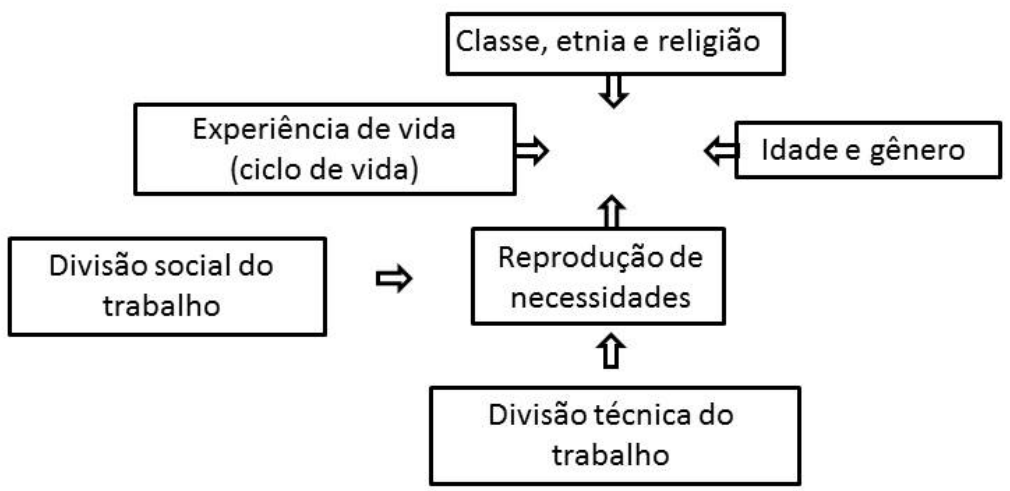

Figura 2 - Condições determinante para a reprodução das necessidades. Adaptado de: Vasconcellos (2014). 


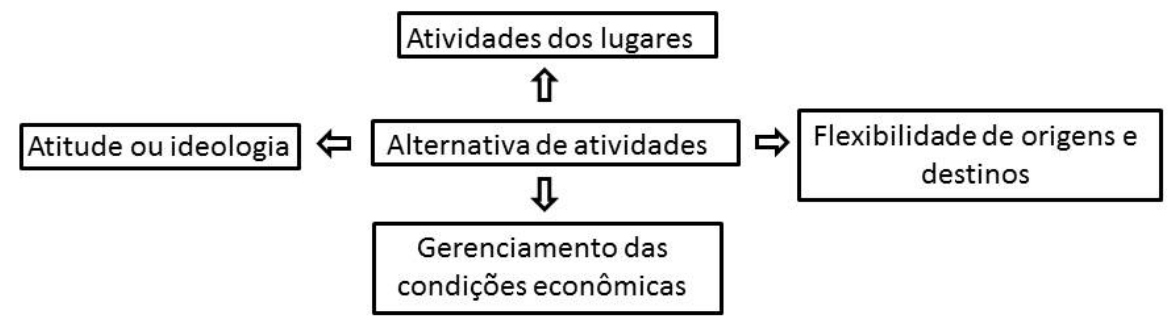

Figura 3 - Fatores determinantes para encontrar uma alternativa para realização de uma atividade.

Adaptado de: Fernandes (2017).

A Figura 3 mostra que, além de buscar uma atividade em outro lugar, com base na atratividade, existem outras alternativas para realizar a atividade sobre o contexto de viagem impossível. Dentre estas outras alternativas, existe a possibilidade de alterar a atitude ou ideologia, isso quer dizer que existem indivíduos que podem escolher entre usar transporte público ou privado, entretanto para cada indivíduo existe uma preferência ou resistência frente a essas escolhas que podem suprimir a viagem. Estas atitudes intimamente relacionadas com os fatores determinantes na reprodução de necessidades.

Outra alternativa é o gerenciamento das condições socioeconômicas. Ou seja, se a viagem é suprimida em condições normais (entendidas como esperadas), pode existir a alternativa de sacrificar gastos pessoais ou familiares (por exemplo com lazer, saúde, educação etc.) para realizar as atividades almejadas, investindo mais do que o esperado para a realização da atividade.

Por último, existe a possibilidade de alternar origens e destinos. Esta alternativa está estreitamente relacionada com as condições socioeconômicas e de atratividade, pois envolve a mudança de residência, local de trabalho ou local de realização das atividades de interesse.

Entende-se que existe uma complexa relação do espaço com o homem, entretanto o espaço oferecido para consumo do homem é intencionalmente criado com uma determinada função e forma (Santos, 2002). Ou seja, esta lógica reforça a ideia dos significados do espaço urbano e de seus lugares.

Desta forma, propõe-se neste artigo analisar a cidade do Rio de Janeiro sob duas perspectivas: cidade para trabalhar e cidade para viver. A cidade para trabalhar estaria seguindo a lógica de potencializar partes da cidade para gerar maior produção e absorção de capital excedente, para os agentes dominantes na produção do espaço urbano, em determinados setores da economia (Harvey, 2008). A cidade para viver segue a lógica de potencializar esta mesma produção e absorção, para todas classes sociais e todos os setores da economia.

Para resumir, esta seção do artigo mostrou as relações intrínsecas entre a produção do espaço urbano e a mobilidade urbana. Existem condições determinantes entre as relações de interesse e necessidade das classes sociais com as funções do espaço urbano. Sendo que os meios de transporte têm o poder de obstruir ou permitir o acesso de "certas" pessoas a "certos" lugares, em um espaço, com uma infraestrutura, intencionalmente moldado para determinados acessos e funções. 


\section{Metodologia de Análise da Cidade para Viver e Trabalhar}

Este artigo propõe uma metodologia quantitativa, utilizando dados oficiais de censo demográfico e de relatórios oficiais de âmbito governamental. A metodologia envolve um processo de análise de dados estatísticos, como média e desvio padrão. Além disso, também se realiza um cálculo de correlação das variáveis específicas da cidade para viver e trabalhar com as variáveis de concentração de atividades e transporte. Ao final, será possível caracterizar as áreas de planejamento em função dos dados da cidade para viver e para trabalhar.

Pelas proporções dos dados da cidade do Rio de Janeiro, decidiu-se definir como áreas de estudo as áreas de planejamento regiões, que reduz a quantidade de áreas de estudo de 160 para 5. As variáveis utilizadas para análise estão apresentadas no Quadro 1. Além disso, é importante destacar que, para os dados do sistema de transporte, considerou-se um cenário em que todos os sistemas estão em funcionamento, mesmo aqueles projetados para 2020.

Os dados de viagens usados foram retirados do Plano Diretor de Transporte Urbano da Região Metropolitana do Rio de Janeiro (Governo do Rio de Janeiro, 2013). Os dados utilizados representam viagens no horário de pico da manhã (7:00 até as 8:00), coletados no ano de 2012, considerando apenas dias uteis.

Quadro 1 - Variáveis Utilizadas na Análise da Cidade para Viver e Trabalhar

\begin{tabular}{|c|c|c|c|}
\hline Variáveis & COD & Descrição & $\begin{array}{l}\text { Viver/ } \\
\text { Trabalho }\end{array}$ \\
\hline $\begin{array}{l}\text { Densidade de empresas/ } \\
\text { atividades }\end{array}$ & DensA & Quantidade de empresas por $\mathrm{km}^{2}$ & $\begin{array}{l}\text { Viver/ } \\
\text { Trabalho }\end{array}$ \\
\hline $\begin{array}{l}\text { Densidade do sistema } \\
\text { de transporte }\end{array}$ & DensT & $\begin{array}{l}\text { Quantidade de estações e paradas } \\
\text { de transporte público (veículo leve } \\
\text { sobre trilhos - VLT, Bus Rapid Tran- } \\
\text { sit - BRT, Ônibus, Trem e Metro) } \\
\text { por km² }\end{array}$ & $\begin{array}{l}\text { Viver/ } \\
\text { Trabalho }\end{array}$ \\
\hline $\begin{array}{l}\text { Densidade demográfica } \\
\text { de habitantes }\end{array}$ & DensH & Habitantes por km² & Viver \\
\hline $\begin{array}{l}\text { Densidade demográfica } \\
\text { de empregados }\end{array}$ & DensE & Empregos por km² & Trabalhar \\
\hline $\begin{array}{l}\text { Renda média dos habitantes } \\
\text { em reais }\end{array}$ & $\mathrm{ReH}$ & $\begin{array}{l}\text { Renda média ponderada dos bair- } \\
\text { ros dentro da região administrati- } \\
\text { va (RA), com base na população } \\
\text { com renda (reais/mês) }\end{array}$ & Viver \\
\hline $\begin{array}{l}\text { Renda média dos emprega- } \\
\text { dos em reais }\end{array}$ & $\operatorname{ReE}$ & $\begin{array}{l}\text { Renda média ponderada dos bair- } \\
\text { ros dentro da RA, com base na po- } \\
\text { pulação empregada }\end{array}$ & Trabalho \\
\hline
\end{tabular}




\begin{tabular}{|c|c|c|c|}
\hline Variáveis & COD & Descrição & $\begin{array}{c}\text { Viver/ } \\
\text { Trabalho }\end{array}$ \\
\hline $\begin{array}{l}\text { Quantidade de viagens de } \\
\text { transporte privado de ori- } \\
\text { gem, por motivo de trabalho } \\
\text { (MT) }\end{array}$ & VpriOT & $\begin{array}{l}\text { Total de viagens de transporte pri- } \\
\text { vado por MT estimada para cada } \\
\text { RA, ponderando a quantidade de } \\
\text { pessoas com renda em cada RA }\end{array}$ & Trabalho \\
\hline $\begin{array}{l}\text { Quantidade de viagens de } \\
\text { transporte privado destina- } \\
\text { dos, por motivo de trabalho } \\
\text { (MT) }\end{array}$ & VpriDT & $\begin{array}{l}\text { Total de viagens de transporte pri- } \\
\text { vado por MT estimada para cada } \\
\text { RA, ponderando a quantidade de } \\
\text { pessoas empregadas em cada RA }\end{array}$ & Trabalho \\
\hline $\begin{array}{l}\text { Quantidade de viagens de } \\
\text { transporte público de ori- } \\
\text { gem, por motivo de trabalho } \\
\text { (MT) }\end{array}$ & VpuOT & $\begin{array}{l}\text { Total de viagens de transporte pú- } \\
\text { blico por MT estimada para cada } \\
\text { RA, ponderando a quantidade de } \\
\text { pessoas com renda em cada RA }\end{array}$ & Trabalho \\
\hline $\begin{array}{l}\text { Quantidade de viagens de } \\
\text { transporte público destina- } \\
\text { dos, por motivo de trabalho } \\
\text { (MT) }\end{array}$ & VpuDT & $\begin{array}{l}\text { Total de viagens de transporte pú- } \\
\text { blico por MT estimada para cada } \\
\text { RA, ponderando a quantidade de } \\
\text { pessoas empregadas em cada RA }\end{array}$ & Trabalho \\
\hline $\begin{array}{l}\text { Quantidade de viagens de } \\
\text { transporte privado de ori- } \\
\text { gem, por outros motivos } \\
\text { (OM) }\end{array}$ & VpriOM & $\begin{array}{l}\text { Total de viagens de transporte pri- } \\
\text { vado por OM estimada para cada } \\
\text { RA, ponderando a população resi- } \\
\text { dente em cada RA }\end{array}$ & Viver \\
\hline $\begin{array}{l}\text { Quantidade de viagens de } \\
\text { transporte privado desti- } \\
\text { nados, por outros motivos } \\
\text { (OM) }\end{array}$ & VpriDM & $\begin{array}{l}\text { Total de viagens de transporte pri- } \\
\text { vado por OM estimada para cada } \\
\text { RA, ponderando a quantidade de } \\
\text { empresas em cada RA }\end{array}$ & Viver \\
\hline $\begin{array}{l}\text { Quantidade de viagens de } \\
\text { transporte público de ori- } \\
\text { gem, por outros motivos } \\
\text { (OM) }\end{array}$ & VpuOM & $\begin{array}{l}\text { Total de viagens de transporte pú- } \\
\text { blico por OM estimada para cada } \\
\text { RA, ponderando a população resi- } \\
\text { dente em cada RA }\end{array}$ & Viver \\
\hline $\begin{array}{l}\text { Quantidade de viagens de } \\
\text { transporte público desti- } \\
\text { nados, por outros motivos } \\
\text { (OM) }\end{array}$ & VpuDM & $\begin{array}{l}\text { Total de viagens de transporte pú- } \\
\text { blico por OM estimada para cada } \\
\text { RA, ponderando quantidade de } \\
\text { empresas em cada RA }\end{array}$ & Viver \\
\hline
\end{tabular}

Fonte: MPRJ (2017), Prefeitura do Rio de Janeiro (2014)

e Governo do Rio de Janeiro (2013). 


\section{Contexto Atual da Cidade do Rio de Janeiro}

Nesta seção, a contextualização da cidade do Rio de Janeiro será baseada nas macrozonas de ocupação e sistema de transporte da cidade. A cidade do Rio de Janeiro está dividida em 5 áreas de planejamento (Figura 4), 34 regiões administrativas e 160 bairros. Além disso, com uma população aproximada de 6 milhões de habitantes, com índices preocupantes de desigualdade social e desigualdade no acesso a serviços de educação, saúde, lazer etc. Além disso, existe uma distribuição desigual das tecnologias de encolhimento do espaço, em específico, o transporte - tecnologia que permite aos habitantes da cidade alcançarem e realizarem as atividades. $\mathrm{Ou}$ seja, o transporte não é o objetivo, mas o meio para um fim. Desta forma, para uma cidade da proporção do Rio de Janeiro, monocêntrica e com destacada desigualdade socioespacial, a oferta de serviços de transporte pode ser um facilitador ou obstáculo para aqueles quem percorrem longas distancias casa-trabalho e possuem condições financeiras desfavoráveis.

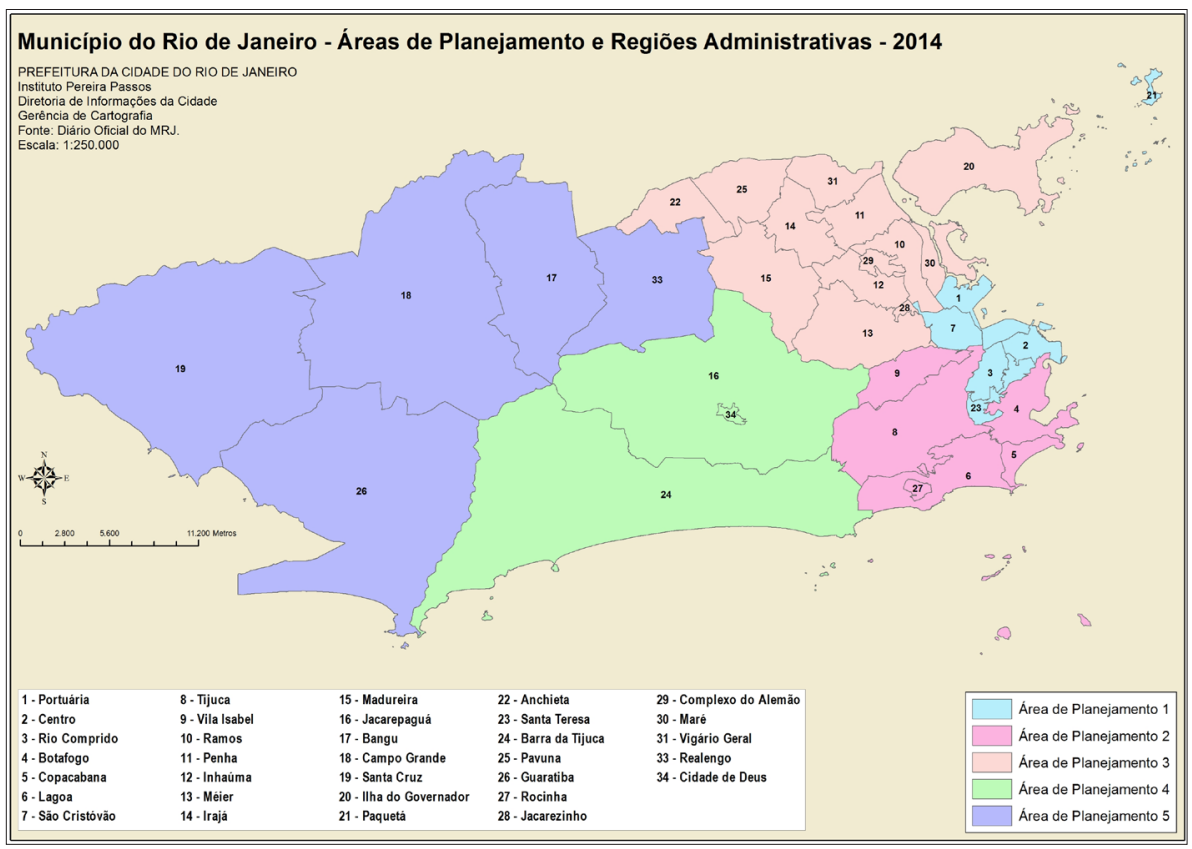

Figura 4 - Áreas de Planejamento e Regiões Administrativas da Cidade do Rio de Janeiro.

Para contextualizar a cidade do Rio de Janeiro, apresenta-se a definição das macrozonas de ocupação, que são divididas em 4 (Figura 5 e Quadro 2). Percebe-se que o recorte geográfico das macrozonas não condiz exatamente com a divisão das áreas de 
planejamento. A definição das macrozonas é apresentada a seguir (Prefeitura do Rio de Janeiro, 2011, p. 20):

"I - Macrozona de Ocupação Controlada, onde o adensamento populacional, a intensidade construtiva serão limitados, a renovação urbana se dará preferencialmente pela reconstrução ou pela reconversão de edificações existentes e o crescimento das atividades de comércio e serviços em locais onde a infraestrutura seja suficiente, respeitadas as áreas predominantemente residenciais;

II - Macrozona de Ocupação Incentivada, onde o adensamento populacional, a intensidade construtiva e o incremento das atividades econômicas e equipamentos de grande porte serão estimulados, preferencialmente nas áreas com maior disponibilidade ou potencial de implantação de infraestrutura;

III - Macrozona de Ocupação Condicionada, onde o adensamento populacional, a intensidade construtiva e a instalação das atividades econômicas serão restringidos de acordo com a capacidade das redes de infraestrutura e subordinados à proteção ambiental e paisagística, podendo ser progressivamente ampliados com o aporte de recursos privados;

IV - Macrozona de Ocupação Assistida, onde o adensamento populacional, o incremento das atividades econômicas e a instalação de complexos econômicos deverão ser acompanhados por investimentos públicos em infraestrutura e por medidas de proteção ao meio ambiente e à atividade agrícola."

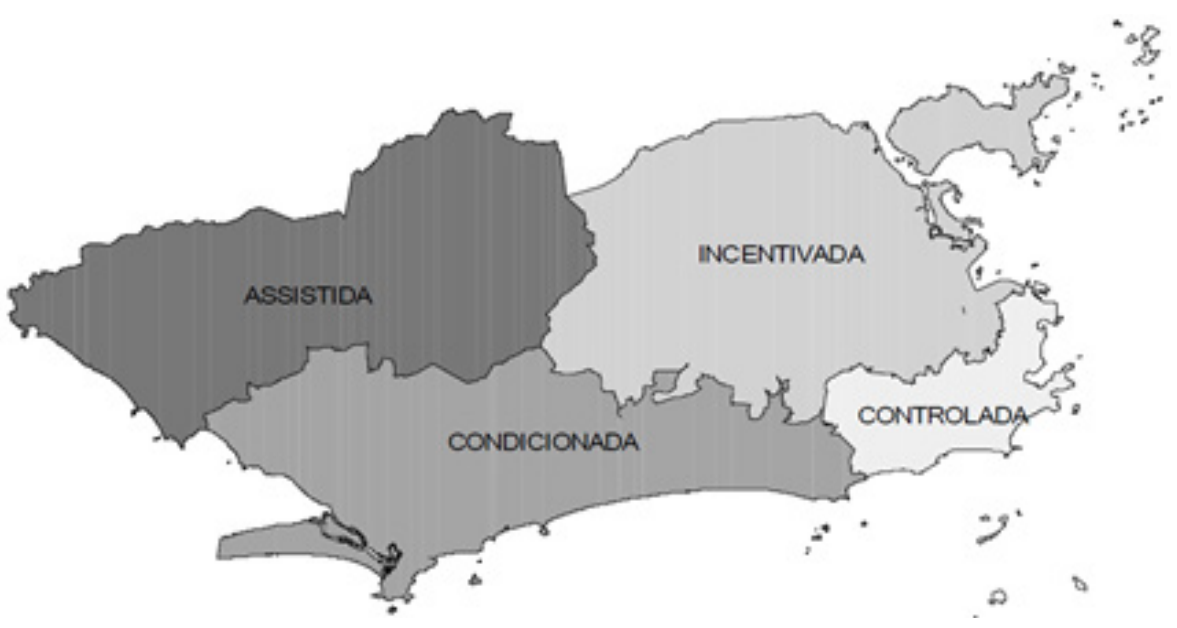

Figura 5 - Divisão das Macrozonas de Ocupação na Cidade do Rio de Janeiro Fonte: Prefeitura do Rio de Janeiro (2011). 
Cidade para Viver ou Trabalhar? Contradições da Distribuição de Atividades, Transporte...

Quadro 2: Macrozonas de Ocupação e Áreas de Planejamento da Cidade do Rio de Janeiro

\begin{tabular}{|c|c|c|}
\hline Macrozonas & $\begin{array}{l}\text { Regiões de } \\
\text { Planejamento }\end{array}$ & $\begin{array}{c}\text { Regiões } \\
\text { Administrativas }\end{array}$ \\
\hline \multirow{3}{*}{ Controlada } & AP 1.1Centro & $\begin{array}{l}\text { II - Centro; XXI - Ilha de Paquetá; XXIII - San- } \\
\text { ta Teresa }\end{array}$ \\
\hline & AP 2.1 Zona Sul & $\begin{array}{l}\text { IV - Botafogo; V - Copacabana; VI - Lagoa; } \\
\text { XXVII - Rocinha }\end{array}$ \\
\hline & AP 2.2 Tijuca & VIII - Tijuca (parte) - Alto da Boavista \\
\hline \multirow{6}{*}{ Incentivada } & AP 1.1Centro & $\begin{array}{l}\text { I - Portuária; III - Rio Comprido; VII - São } \\
\text { Cristóvão }\end{array}$ \\
\hline & AP 2.2 Tijuca & $\begin{array}{l}\text { VIII - Tijuca (parte) - excluído Alto da Boavis- } \\
\text { ta; IX - Vila Isabel }\end{array}$ \\
\hline & AP 3.I Ramos & X - Ramos; XXX - Complexo da Maré \\
\hline & AP 3.2 Méier & XIII - Méier; XXIX - Jacarezinho \\
\hline & AP 3.3 Madureira & XIV - Irajá; XV - Madureira \\
\hline & AP 3.4 Inhaúma & XII - Inhaúma; XXIV - Complexo do Alemão \\
\hline \multirow{5}{*}{ Incentivada } & AP 3.5 Penha & XI - Penha; XXXI - Vigário Geral \\
\hline & AP 3.6 Pavuna & XXII - Anchieta; XXV - Pavuna \\
\hline & AP 3.7 Ilha Governador & XX - Ilha do Governador \\
\hline & AP 4.1 Jacarepaguá & $\begin{array}{l}\text { XVI - Jacarepaguá (parte) - excluída a área } \\
\text { do Decreto N. 3.046, de } 27 \text { de abril de 1981; } \\
\text { XXXIV - Cidade de Deus }\end{array}$ \\
\hline & AP 5.I Bangu & XXXIII - Realengo \\
\hline \multirow{3}{*}{ Condicionada } & AP 4.1 Jacarepaguá & $\begin{array}{l}\text { XVI - Jacarepaguá (parte) - área do Decreto } \\
\text { número 3.046, de } 27 \text { de abril de } 1981\end{array}$ \\
\hline & AP 4.2 Barra da Tijuca & XXXVI - Barra da Tijuca \\
\hline & AP 5.4 Guaratiba & XXVI - Guaratiba \\
\hline \multirow{3}{*}{ Assistida } & AP 5.1 Bangu & XVII - Bangu \\
\hline & $\begin{array}{l}\text { AP } 5.2 \text { Campo } \\
\text { Grande }\end{array}$ & XVII - Campo Grande \\
\hline & AP 5.3 Santa Cruz & XIX - Santa Cruz \\
\hline
\end{tabular}

Fonte: Prefeitura do Rio de Janeiro (2011). 
A macrozona de ocupação controlada envolve, aproximadamente, a AP 1 e 2, onde admite-se que existe uma alta densidade demográfica e pouco espaço de expansão urbana, sendo desta forma uma prioridade em renovação de urbana, reconstrução ou reconversão de edifícios e estimulando o crescimento de comércio e serviços aproveitando a infraestrutura existente (incluindo transporte). Com relação ao sistema de transporte, observa-se que esta área converge os sistemas de transporte sobre trilhos, ciclovias, possui alta densidade de paradas de ônibus convencional (Figura 6) e a futuramente vai convergir o sistema BRT (Bus Rapid Transit), através da linha Transbrasil (Figura 7).

A macrozona de ocupação consiste, em sua maior parte a AP 3, onde existe um interesse de incentivar o adensamento populacional e de área construída. Além disso, também existe o interesse de incentivar o crescimento de atividades econômicas, implementação de equipamentos de grande porte (exemplo, shopping centers), em áreas com disponibilidade ou potencial de implantação de infraestrutura. Em termos de transporte, esta área possui acesso aos sistemas de trem, metro, BRT e ônibus convencional (Figura 6). E algumas áreas de favelas, como complexo do alemão, possui teleférico para facilitar o acesso dos habitantes aos sistemas de transporte já mencionados. Até 2020, a AP 3 também vai ter acesso direto ao centro através da Transbrasil (Figura 7).

A macrozona de ocupação condicionada envolve, em sua maior parte, a AP 4, onde o adensamento populacional, intensidade construtiva e instalação de atividades econômicas serão restringidos, de acordo com a rede de infraestrutura (pode-se ler transporte), buscando a proteção ambiental, e com possível expansão urbana com aporte do setor privado. Com base na Figura 6, esta área possui basicamente acesso ao sistema de BRT e ônibus convencional, e recentemente entrou em funcionamento a linha 4 do metrô que chega no Jardim Oceânico (Figura 7), permitindo conexão com o BRT. Pode-se observar que o sistema de transporte nesta área é menos disperso e denso geograficamente, em comparação a AP 1, 2 e 3.

A macrozona de ocupação assistida consiste, basicamente, na AP 5, onde se admite que o adensamento populacional e incremento de atividades e complexos econômicos deverão ser acompanhados por investimentos públicos em infraestrutura urbana, respeitando o meio ambiente e atividades agrícolas. Em termos de transporte, é uma área com acesso ao BRT, sistema de ônibus convencional e trem urbano. 
Cidade para Viver ou Trabalhar? Contradições da Distribuição de Atividades, Transporte...

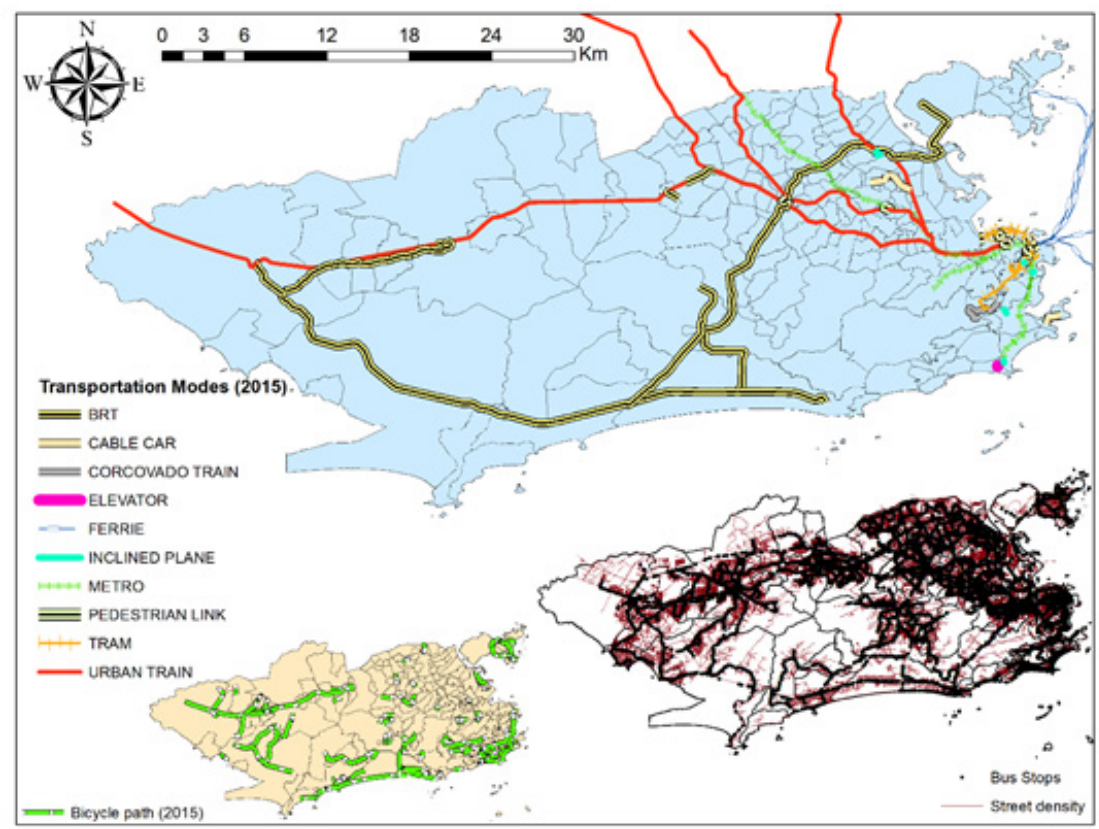

Figura 6 - Sistema de transporte existente até 2015, na cidade do Rio de Janeiro (Fernandes, 2017).

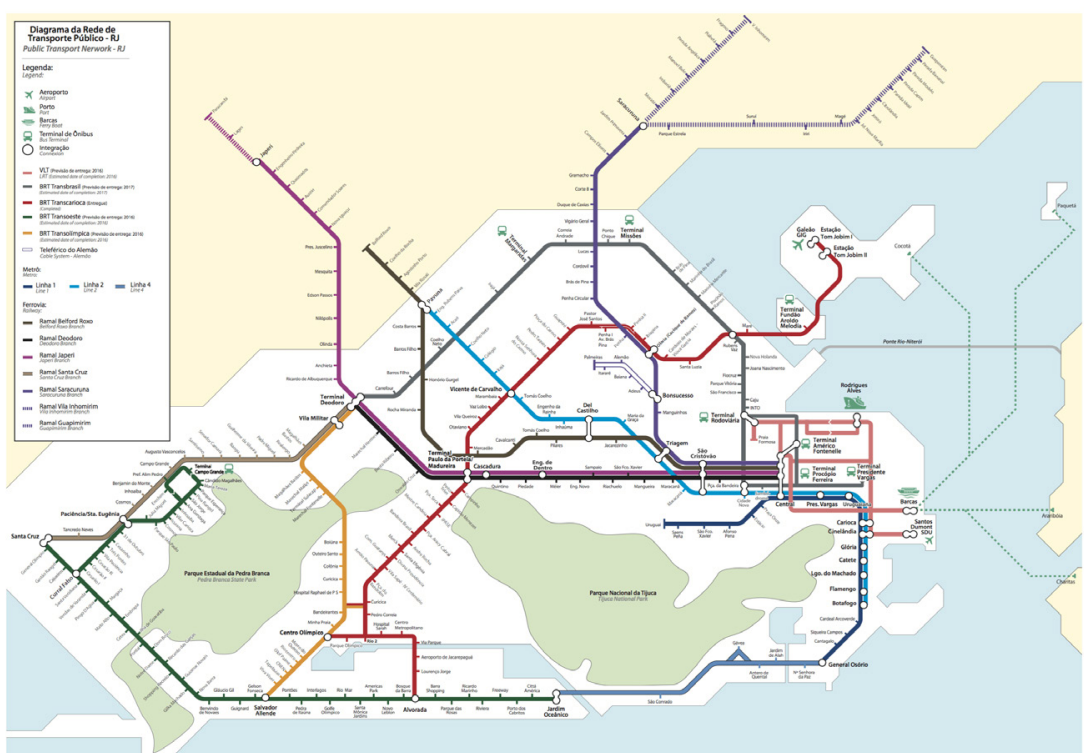

Figura 7: Sistema de transporte esperado até 2020, na cidade do Rio de Janeiro (Prefeitura do Rio de Janeiro, 2017). 
É possível observar que o plano diretor da cidade do Rio de Janeiro, de 2011, destaca diferentes políticas e interesses distribuídos pela cidade, construídos ao longo da história. É importante destacar que Abreu (2008) já afirmava que modelos de crescimento urbano de países desenvolvidos não podem ser aplicados em cidades brasileiras, pelos diferentes padrões de crescimento urbano e das mudanças socioeconômicas no espaço e no tempo.

A área de planejamento 1 representa o epicentro da urbanização do Rio de Janeiro, desde o século XIX (Abreu, 2008). A expansão das linhas de trem urbano para AP 3, no final do século XIX, refletiu uma expansão das indústrias nesta área e, consequentemente, um adensamento populacional dos trabalhadores destes estabelecimentos na região. Enquanto, no século XX, implementou e expandiu-se o metrô no sentido AP 2, atendendo a uma classe trabalhadora mais qualificada e com rendas mais elevadas que trabalhavam no centro de negócios do Rio de Janeiro, e para AP 3 atendendo a uma classe trabalhadora menos qualificada com menor renda, para trabalhar na AP 1.

A expansão para o oeste da cidade é marcada pela construção de ruas e avenidas neste sentido, já atendendo a demanda da indústria automobilística em ascensão, em fins do século XX e princípio do século XXI. Já desde então marcando as debilidades do transporte públicos na AP 5 e AP 4 (de Souza Vieira, 2011). O Rio de Janeiro repete padrões observados por Vasconcellos (2014), de forma geral, em diversas cidades de países desenvolvidos. Ou seja, existe melhores condições para o uso de transporte privado em áreas periféricas da cidade, por péssimas condições de uso e acesso a transporte público.

\section{Resultados}

Nesta seção, realiza-se a análise das variáveis propostas para entender o espaço para viver e trabalhar dentro da cidade do Rio de Janeiro. As Tabelas 1 e 2 apresentam as variáveis para analisar a cidade para viver e trabalhar. Para todos os fatores, apresenta-se dados de média e desvio padrão. Além disso, avalia-se por correlação de Pearson as variáveis dependentes, densidade de estabelecimentos econômicos e do sistema de transporte, com as outras variáveis, que podem ser lidas como independentes.

\section{Avaliação da Cidade para Viver}

A correlação das médias das variáveis independentes das APs com as dependentes (densidades de atividades e de transporte público) mostram que, geograficamente, existe uma tendência de maior uso do transporte privado por outros motivos em áreas que possuem alta densidade de atividades e do sistema de transporte público, como a AP 1 e 2. Enquanto que as áreas que geram e recebem viagens por transporte público, por outros motivos, possuem uma baixa correlação com a densidade de atividades (Tabela 1). 
Cidade para Viver ou Trabalhar? Contradições da Distribuição de Atividades, Transporte...

Tabela 1 - Variáveis para Avaliar a Cidade para Viver

\begin{tabular}{|c|c|c|c|c|c|c|c|c|}
\hline Variáveis & Medidas & AP1 & AP2 & AP3 & AP4 & AP5 & $\begin{array}{c}\text { Correl } \\
(1)^{1}\end{array}$ & $\begin{array}{c}\text { Correl } \\
(2)^{2}\end{array}$ \\
\hline \multirow{2}{*}{ DensA (1) } & Média & 521 & 530 & 203 & 112 & 28 & \multirow{2}{*}{1,00} & \multirow{2}{*}{0,98} \\
\hline & Desvpad & $177 \%$ & $87 \%$ & $90 \%$ & $78 \%$ & $79 \%$ & & \\
\hline \multirow{2}{*}{ DensT (2) } & Média & 113 & 101 & 59 & 27 & 19 & \multirow{2}{*}{0,98} & \multirow{2}{*}{1,00} \\
\hline & Desvpad & $78 \%$ & $77 \%$ & $69 \%$ & $90 \%$ & $85 \%$ & & \\
\hline \multirow{2}{*}{ DensH } & Média & 11845 & 14199 & 12584 & 6879 & 4553 & \multirow{2}{*}{0,83} & \multirow{2}{*}{0,86} \\
\hline & Desvpad & $54 \%$ & $70 \%$ & $34 \%$ & $100 \%$ & $82 \%$ & & \\
\hline \multirow{2}{*}{$\mathrm{ReH}$} & Média & 835 & 3832 & 1032 & 1840 & 761 & \multirow{2}{*}{0,49} & \multirow{2}{*}{0,35} \\
\hline & Desvpad & $46 \%$ & $40 \%$ & $41 \%$ & $86 \%$ & $39 \%$ & & \\
\hline \multirow{2}{*}{ VpriOM } & Média & 751 & 704 & 224 & 535 & 432 & \multirow{2}{*}{0,72} & \multirow{2}{*}{0,63} \\
\hline & Desvpad & $66 \%$ & $107 \%$ & $70 \%$ & $87 \%$ & $107 \%$ & & \\
\hline \multirow{2}{*}{ VpriDM } & Média & 1001 & 688 & 211 & 396 & 483 & \multirow{2}{*}{0,75} & \multirow{2}{*}{0,73} \\
\hline & Desvpad & $287 \%$ & $123 \%$ & $110 \%$ & $197 \%$ & $173 \%$ & & \\
\hline \multirow{2}{*}{ VpuOM } & Média & 1591 & 634 & 631 & 664 & 1472 & \multirow{2}{*}{0,04} & \multirow{2}{*}{0,10} \\
\hline & Desvpad & $66 \%$ & $107.3 \%$ & $70 \%$ & $87 \%$ & $107.1 \%$ & & \\
\hline \multirow{2}{*}{ VpuDM } & Média & 2039 & 703 & 625 & 506 & 1495 & \multirow{2}{*}{0,26} & \multirow{2}{*}{0,33} \\
\hline & Desvpad & $287 \%$ & $123 \%$ & $110 \%$ & $197 \%$ & $173 \%$ & & \\
\hline
\end{tabular}

1 - correlação de todas as variáveis das APs com a variável de densidade de atividades.

2 - correlação de todas as variáveis das APs com a variável de densidade de transporte.

Apesar de AP 2 e AP 1 apresentarem valores similares em relação à média da densidade de atividades e de paradas/estações de transporte público por bairro, existe uma destacada diferença em relação à renda média dos habitantes, que são de R 3.832 para AP 2 e R\$ 835 para AP 1. Além disso, a AP 1 apresenta maior desvio padrão da densidade de atividades dos bairros, porque esta área possui bairros como o Centro, com 3.384 empresas por $\mathrm{km}^{2}$, e bairros como Caju, Santa Teresa e Mangueira, com respectivamente, 28, 55 e 46 empresas por $\mathrm{km}^{2}$, que também possuem rendas medias abaixo do valor do Centro.

Por outro lado, a AP 2 possui menor desvio padrão da densidade de empresas e de renda média por bairro. Esta área também apresenta uma quantidade menor média de viagens de saída por bairro para outras APs, tanto por transporte privado quanto 
público, em comparação com a AP 1. Isso pode representar uma menor necessidade de sair desta área, por já apresentar uma oferta de serviços compatíveis com as necessidades dos habitantes. Todas as variáveis de viagens de transporte público e privado se destacam pelos altos valores de desvio padrão. Com exemplo, pode-se citar bairros como Copacabana e Tijuca, com valores acima de 2000 viagens geradas e recebidas por transporte público e privado por bairro, com renda média acima de 3000 reais, e bairros como Vidigal e Andaraí, com viagens geradas e recebidas por transporte privado e público abaixo de 1000 por bairro, com renda média abaixo de 2000 reais.

A AP 3 é a área com a terceira maior média de empresas e paradas/estações de transporte por $\mathrm{km}^{2}$ por bairro, entretanto com uma menor renda média, em comparação com as AP 1, 2 e 4. Em relação às viagens geradas e recebidas por transporte privado, chegam a ser aproximadamente 3 vezes menores do que a AP 1 e 2, com uma quantidade de viagens produzidas e recebidas por transporte público similar à AP 2. Assim como a AP 2, a AP 3 apresenta, possivelmente, serviços compatíveis com as necessidades daqueles que vivem nesta área ou de pessoas de renda similar de outras APs, e dependentes do transporte público para a movimentação. Na AP 3, em termos de desvio padrão, existe um maior destaque nas viagens recebidas por transporte público, pois possuem bairros como Madureira e Bonsucesso, com aproximadamente 3.000 viagens recebidas, com renda média dos habitantes de aproximadamente $\mathrm{R} \$ 1.000$, e bairros como Pavuna e Maguinhos com menos de 1.000 viagens recebidas por transporte público, e com renda média abaixo de R\$1.000.

A AP 4 apresenta baixa densidade de atividades e do sistema de transporte público. Entretanto possui a segunda maior renda média. Esta área de planejamento possui valores similares a AP 2 de geração e recebimento de viagens por transporte público e privado. A AP 4 possui maior destaque na dispersão da média em relação às variáveis relacionadas às viagens recebidas por transporte privado e público. Esta AP possui a Barra da Tijuca, com mais de 3000 viagens por transporte público e privado, com renda média de R \$ 5.940, enquanto os outros bairros na região de Jacarepaguá, por exemplo, cada uma recebendo menos de 1000 viagens por transporte público e privado, com renda média variando de $\mathrm{R} \$ 1.000$ a $\mathrm{R} \$ 2.000$.

A AP 5 possui menores valores de densidade de atividades, transporte público e menor renda média. Esta área possui a segunda maior geração e recebimento de viagens de transporte público e privado. Entretanto, ela se destaca por receber maior parte destas viagens por outros municípios do Estado do Rio. Esta área possui uma dispersão relevante das viagens geradas e recebidas entre os bairros. Por exemplo, a AP possui bairros como Bangu e Campo Grande, com mais de 5000 viagens recebidas por transporte público cada um, com renda média variando de $\mathrm{R} \$ 650$ a $\mathrm{R} \$ 880$ reais. Ou seja, pode-se esperar que os serviços oferecidos nesta área sejam compatíveis com o nível de renda dos habitantes desta AP e de habitantes de outras APs com renda similar.

\section{Avaliação da cidade para trabalhar}

É possível observar com a correlação estatística realizada com os dados das APs, que existe uma correlação negativa das viagens geradas por transporte público e privado, e 
Cidade para Viver ou Trabalhar? Contradições da Distribuição de Atividades, Transporte...

alta correlação das viagens destinadas pelos mesmos meios, com relação a densidade de atividades e do sistema de transporte. Ou seja, as APs que geram maior quantidade de viagem tendem a ter menor densidade de empresas e do sistema de transporte público. Além disso, as áreas onde os empregados ganham maior salários, possuem também maior concentração de empresas e maior acesso ao transporte público (Tabela 2).

Tabela 2: Variáveis para Avaliar a Cidade para Trabalhar.

\begin{tabular}{|c|c|c|c|c|c|c|c|c|}
\hline Variáveis & Medidas & AP1 & AP2 & AP3 & AP4 & AP5 & $\begin{array}{c}\text { Correl } \\
(1)^{1}\end{array}$ & $\begin{array}{c}\text { Correl } \\
(2)^{2}\end{array}$ \\
\hline \multirow{2}{*}{ DensA (1) } & Média & 521 & 530 & 203 & 112 & 28 & \multirow{2}{*}{1,00} & \multirow{2}{*}{0,98} \\
\hline & Desvpad & $177 \%$ & $87 \%$ & $90 \%$ & $78 \%$ & $79 \%$ & & \\
\hline \multirow{2}{*}{ DensT (2) } & Média & 113 & 101 & 59 & 27 & 19 & \multirow{2}{*}{0,98} & \multirow{2}{*}{1,00} \\
\hline & Desvpad & $78 \%$ & $77 \%$ & $69 \%$ & $90 \%$ & $85 \%$ & & \\
\hline \multirow[t]{2}{*}{ DensE } & Média & 30072 & 7184 & 3052 & 1527 & 351 & \multirow{2}{*}{0,74} & \multirow{2}{*}{0,79} \\
\hline & Desvpad & $144 \%$ & $85 \%$ & $125 \%$ & $88 \%$ & $73 \%$ & & \\
\hline \multirow{2}{*}{ ReE } & Média & 2579 & 2679 & 1743 & 1831 & 1699 & \multirow{2}{*}{0,97} & \multirow{2}{*}{0,92} \\
\hline & Desvpad & $41 \%$ & $38 \%$ & $59 \%$ & $42 \%$ & $66 \%$ & & \\
\hline \multirow{2}{*}{ VpriOT } & Média & 519 & 843 & 285 & 720 & 908 & \multirow{2}{*}{$-0,13$} & \multirow{2}{*}{$-0,27$} \\
\hline & Desvpad & $72.2 \%$ & $106 \%$ & $71.5 \%$ & $88 \%$ & $119 \%$ & & \\
\hline \multirow[t]{2}{*}{ VpriDT } & Média & 1655 & 756 & 271 & 761 & 620 & \multirow{2}{*}{0,60} & \multirow{2}{*}{0,61} \\
\hline & Desvpad & $224 \%$ & $127 \%$ & $133 \%$ & $214 \%$ & $171 \%$ & & \\
\hline \multirow{2}{*}{ VpuOT } & Média & 2701 & 2125 & 1824 & 2259 & 2966 & \multirow{2}{*}{$-0,17$} & \multirow{2}{*}{$-0,17$} \\
\hline & Desvpad & $72 \%$ & $106 \%$ & $72 \%$ & $88 \%$ & $119 \%$ & & \\
\hline \multirow{2}{*}{ VpuDT } & Média & 9997 & 3232 & 1096 & 3060 & 1485 & \multirow{2}{*}{0,67} & \multirow{2}{*}{0,70} \\
\hline & Desvpad & $224 \%$ & $127 \%$ & $133 \%$ & $214 \%$ & $171 \%$ & & \\
\hline
\end{tabular}

1 - correlação de todas as variáveis das APs com a variável de densidade de atividades. 2 - correlação de todas as variáveis das APs com a variável de densidade de transporte.

Pode-se observar que as APs 1 e 2 se destacam pelos mais altos valores relacionados às variáveis dependentes, como apontado na análise do espaço para viver. Além disso, por serem áreas que geram maiores salários, em comparação com a AP 3, 4 e 5. 
Com relação às viagens, a AP 1 se destaca por receber maior quantidade de viagens a trabalho por transporte público e privado, possuir um dos menores valores de geração de viagens por transporte privado e apresentar segunda maior quantidade de viagens geradas por transporte público. Estas informações podem ser um reflexo da importância da AP 1 como centro de negócios, o tipo de atividades envolvidas que geram rendas maiores, e as condições dos habitantes desta área, que apresentam uma média de renda não compatível com a média de renda gerada. As viagens de destino à AP 1 apresenta valores significantes de desvio padrão, por conta da diferença em relação à densidade de empresas e empregos em cada bairro. Por exemplo, o Centro possui $65 \%$ de todos os empregos da AP 1, enquanto existem bairros como Mangueira e Gamboa com menos de $1 \%$ dos empregos desta AP.

A AP 2 apresenta também maior média da renda gerada por habitante em relação à AP 3, 4 e 5. Esta área se destaca por possuir uma alta geração de viagens por transporte privado e público, e maior recebimento de viagens por transporte público. Em relação às viagens geradas por transporte público, esta área apresenta um dos menores valores. Estes valores mostram que esta AP oferece empregos com a maior média de salário por bairro na cidade do Rio de Janeiro. Além disso, assim como esta área possui a maior média de renda por bairro por habitante, ela também apresenta maior média de salário por empregado. Possivelmente, há maior compatibilidade entre as características da população desta AP com os tipos de trabalhos existentes. Quanto aos valores de desvio padrão, esta área apresenta uma variação significante entre os bairros das viagens geradas e produzidas por transporte público e privado. Esta variação pode estar relacionada a uma distribuição desigual dos empregos, renda dos habitantes e dos trabalhadores. Por ser uma área de alta densidade demográfica e diversidade socioeconômica, possivelmente, existem habitantes desta área que necessitam buscar empregos em outras APs, por não possuírem a qualificação necessária, e outros que não necessitam trabalhar em outras APs, pois estão mais compatíveis com os empregos oferecidos nesta $\mathrm{AP}$, que em média oferece maiores salários, em relação às outras APs da cidade. Por exemplo, existe o bairro de Andaraí, em que a média de salário dos habitantes é de R\$1.942, enquanto a média de salário das pessoas que trabalham nesta área é de R\$ 3.259 .

A AP 3 possui a terceira maior média de densidade do sistema de transporte público e de empresas. Esta área apresenta as menores medias de viagens geradas e recebidas por bairro. Apesar desta área possuir a terceira maior densidade de empregados por $\mathrm{km}^{2}$ por bairro. A AP 3, possivelmente, possui maior compatibilidade entre tipos de empregos e interesse (necessidades) dos habitantes, desta forma gerando menores viagens de saída e chegada nesta AP. Mas, de qualquer forma, ainda existe um fluxo de saída e entrada desta AP, sendo as de saída menores que o fluxo de entrada. Em relação aos valores de desvio padrão, esta AP se destaca pela variação de viagens que chegam nos bairros desta AP, sendo uma consequência da variação na quantidade de empregos e empresas entre os bairros. Como exemplo, esta área possui o bairro de Bonsucesso com $12 \%$ e Madureira com $5 \%$ de todos os empregos da AP 3, enquanto a maioria dos outros bairros apresentam valores próximos ou menores do que $1 \%$. 
A AP 4 apresenta características inversas da AP 3, por possuir menores densidades de empresas, do sistema de transporte e empregados. Entretanto, esta área apresenta uma maior média de renda dos empregados, e possui médias similares à AP 2 de viagens geradas e recebidas por transporte privado e público. É interessante observar que a renda média dos habitantes é similar à renda média dos trabalhadores. Possivelmente, esta área já possui uma quantidade significante de habitantes desta AP que trabalham nesta área. Entretanto, esta área também atrai pessoas de outras APs por motivo de trabalho. Em termos de desvio padrão, esta área apresenta diferenças significativas no destino das viagens entre os bairros, por conta das diferenças de densidade de empresas e empregos. Por exemplo, Barra da Tijuca consiste em 52\% dos empregos de toda a AP 4, enquanto bairros como Camorin e Cidade de Deus possuem menos de $1 \%$.

A AP 5 possui as menores médias de densidade de atividades por bairro, do sistema de transporte, de empregados e menor média de renda dos trabalhadores por bairro. Em termos de viagens, é uma área que gera mais viagens do que recebe por transporte privado e público. Esta área possui diferenças significantes entre os bairros das viagens geradas e recebidas por transporte público e privado. Esta área possui a menor diferença entre os bairros em relação à distribuição de empresas e empregos, entretanto ainda em baixa quantidade e, talvez, muitos empregos não compatíveis com a qualificação dos habitantes, mas compatíveis com habitantes de outros municípios do Rio de Janeiro e APs da cidade. Estas características podem ter relação com o distanciamento geográfico desta área do Central Business District (CBD), na AP 1.

\section{Conclusões}

Este artigo buscou identificar a existência de diferenças entre a cidade para viver, com base nas viagens realizadas por outros motivos, e a cidade para trabalhar, com base nas viagens a trabalho. Foi possível observar que, apesar de a AP 5 apresentar menores densidade de atividades e de serviços de transporte, esta área possui atrativos para pessoas se destinarem a esta AP por outros motivos, enquanto que, para as viagens a trabaIho, esta área apresentou menor destaque.

Sendo a AP 5 uma macrozona de ocupação assistida, admitiu-se que o desenvolvimento desta área deve vir com um acompanhamento de investimentos públicos em infraestrutura. Entretanto, a AP 5 possui pouco acesso ao sistema de transporte público e além disso existe um potencial não admitido na definição da macrozona. Por exemplo, observou-se que existe uma quantidade significativa de viagens por outros motivos para esta área. Ou seja, existe uma economia local representativa, e mesmo assim a AP 5 recebeu os menores investimentos em transporte em comparação com outras APs, pois apenas implementaram o BRT, enquanto, na AP 4, já implementaram uma estação de metrô e o sistema de BRT, que é uma área mais recente de expansão urbana.

A AP 1 é uma área onde os habitantes tendem a ter menor renda, entretanto esta área possui o Central Business District da cidade (Centro), onde existe uma quantidade grande de empregos que geram maior renda, em consequência também criando uma demanda de serviços para este público, que necessariamente não vive nesta área. E por outro lado, possivelmente, estes serviços são inacessíveis para a população de baixa renda da região. 
Desta forma, como um espaço para viver, a AP 1 gera uma quantidade alta de viagens de saída de seus habitantes e uma quantidade alta de viagens de entrada de habitantes de outra APs, possivelmente, com maior renda. Como um espaço de trabalho, a AP 1 é a que possui maior atratividade, tanto para viagens por transporte privado quanto público, e oferecendo maior média de renda para seus trabalhadores.

A AP 2 se destaca como uma cidade para viver e trabalhar, uma vez que, em comparação com os dados das outras APs, ela se destaca nos dois tipos de dados. É uma área que apresenta atrativos de trabalho e de serviços, além de possuir alta densidade de serviços de transporte e menor desigualdade de renda, tanto dos habitantes quanto dos trabalhadores.

A definição de macrozona de ocupação controlada apresentado na seção 4 condiz com os dados analisados neste artigo, da AP 2. Entretanto, não se pode separar a sociedade do espaço. Desta forma, projetos de renovação urbana, reconstrução ou reconversão de edifícios para estimular o crescimento de comércios e serviços, possivelmente, corre o risco de continuar não incluindo a população local, por incompatibilidade da reprodução de necessidades dos habitantes e a atratividade do espaço para eles.

A AP 3 é uma área que pode ser vista como um espaço para viver e trabalhar, entretanto atendendo aos seus habitantes, com base em seus níveis socioeconômicos. Além disso, a AP 3, em termos de viagens de trabalho e por outros motivos, é a área com os menores médias de viagem por bairro, em comparação com as outras APs. Entretanto, é uma área que apresenta alta densidade de atividades, de serviços de transporte e densidade demográfica. Desta forma, possivelmente, é uma área com mais circulação interna por fins de trabalho e outros motivos, que não está contabilizado neste artigo.

Vendo a AP 3 como macrozona de ocupação incentivada, admite-se que o adensamento populacional, expansão da área construída e crescimento das atividades econômicas serão incentivadas. Entretanto, esta área já é uma área adensada e possui maior acesso a transporte público em comparação com a AP 4 e 5 . Além disso, a implementação de equipamentos de grande porte (exemplo, shopping centers e franquias estabelecidas no mercado brasileiro) pode ser prejudicial para a economia local e também corre o risco de não ser compatível com os interesses dos habitantes desta área. Pois esta área possui a terceira maior média de empregos por bairros que, possivelmente, dependem das atividades e serviços já existentes.

A AP 4 é a área que possui maior variação de nível de renda dos seus habitantes e uma das menores variações de renda de seus trabalhadores. Consequentemente, é uma das áreas que menos recebe e mais gera viagens por outros motivos. Enquanto que, para as viagens a trabalho, é uma das áreas que mais recebe e gera viagens. Ou seja, para outros motivos há uma incompatibilidade de interesses dos habitantes com o espaço, por conta da desigualdade socioeconômica. E por motivo de trabalho, possivelmente, existem mais pessoas de maior renda que trabalham nesta $\mathrm{AP}$, enquanto os habitantes de menor renda trabalham em outras APs, que possuem uma renda média do trabalhador mais baixo.

A macrozona de ocupação condicionada, definida como a AP 4 neste artigo, foi definida como uma área em que o adensamento populacional, intensidade construtiva e instalação de atividade econômicas serão restringidos. Entretanto, admite-se também que para esta área será buscado investimentos do setor privado. Essa afirmativa contradiz o interesse comum, pois a AP 4, já vem, desde a década de 1970, sofrendo um boom imobiliário, 
atraindo a população de alta renda (Abramo \& Faria, 1998) e, consequentemente, atraindo serviços e atividades compatíveis com os interesses dessa população. Ou seja, pode-se perguntar: incentiva-se o adensamento populacional "onde" e controla-se "onde"?

\section{Considerações Finais e Limitações}

Este artigo é uma tentativa incipiente de diferenciar os espaços da cidade, entendendo que a cidade está dividida em atividades diversas, umas mais ligadas a negócios e outras mais a atividades do dia a dia de um cidadão, como lazer, compras etc. Estas empresas e atividades geram um tipo de renda e viagens que, possivelmente, estão condicionadas as características socioespaciais da cidade.

Com o objetivo de identificar se há diferenças no consumo do espaço urbanos em termos de trabalho e atividades não relacionadas a trabalho, neste artigo, foi possível destacar que existe diferentes padrões de uso da cidade em função dos significados do espaço e distribuição socioespacial. Além disso, observa-se que há uma reprodução de uma lógica que favorece as classes sociais com maior renda, oferecendo maior acesso ao sistema de transporte público. Sendo este comportamento contraditório. Por exemplo, no caso das viagens a trabalho, elas são em sua maioria originadas de áreas com menor acesso a sistemas de transporte público, onde habitam pessoas com menor renda.

Existe um desafio de planejamento urbano na cidade do Rio de Janeiro, no sentido de incentivar a policentralidade para se reduzir a distância das viagens, em especifico a trabalho, em áreas mais distantes do centro da cidade e com menor acesso a serviços de transporte público.

As limitações deste trabalho se destacam pela escala de análise e variáveis utilizadas. Pode-se observar que, dentro das áreas de planejamento, existe uma significativa diferença em questões socioeconômicas, de acesso a serviços de transporte público, e densidade de atividades/empresas e empregos. Além disso, as variáveis de viagens utilizadas foram coletadas em escala de APs e depois ponderadas com base em variáveis de população, emprego e empresas. Desta forma, estes dados podem não representar a realidade por completo. Outra limitação está relacionada com a análise com base em média aritmética, uma vez que estes valores não representam todas as realidades. É necessário buscar outros tipos de variáveis estatísticas que representem, com maior precisão, a realidade da cidade.

Para trabalhos futuros, a intenção é desenvolver um modelo que permita avaliar com maior precisão a cidade para viver e trabalhar, incluindo outros dados que se considera importante, como de nível de educação, de acesso a serviços básicos, dados de movimentação dentro das APs e as escolhas modais, incluindo transporte não motorizado. Para complementar, existe a necessidade de diferenciar os tipos de atividades existentes em cada parte da cidade, não apenas a quantidade.

\section{Agradecimentos}

Esta pesquisa foi financiada pelo Projeto FONDAP n. 15110020 do Centro de Desarrollo Urbano Sustentable (CEDEUS) na Pontificia Universidad Católica de Chile. 


\section{Referências Bibliográficas}

ABRAMO, P.; FARIA, T. C. Mobilidade residencial na cidade do Rio de Janeiro: considerações sobre os setores formal e informal do mercado imobiliário. Caxambu, XI Encontro Nacional de Estudos Populacionais da Abep, 1998. p. 421-456.

ABREU, M. A evolução urbana do Rio de Janeiro. Rio de Janeiro: Instituto Pereira Passos (IPP), 2008.

CAPEL, H. Violencia inequidad, contaminacion y otros problemas en la ciudad actual. ¿Qué hacer? In: BENACH, N.; ALESSANDRI, A. (eds). Pensar la ciudad en tiempos de crisis. Barcelona: Icaria, 2016. p. 225-270.

CARLOS, A. F. A., SOUZA, M. L.; SPOSITO, M. E. B. A produção do espaco urbano. São Paulo: Contexto, 2011.

CASTELLS, M. The city and the grass-roots: cross-cultural theory of urban social movements. Berkeley: Univ. Calif. Press, 1983.

. Urban sociology in the twenty-first century. Cidades - comunidades e território, v. 5, 2002. p. 9-19.

A questão urbana. 4. ed. São Paulo: Paz e Terra, 2009.

VIEIRA, W. S. Memória, identidade, cultura e movimentos sociais na zona oeste carioca. Salvador, s.n., 2001.

FERNANDES, V. A. Resilience of urban mobility in the face of fossil fuel dependency: an empirical study of Rio de Janeiro. Tuebingen: Universitätsbibliothek Tübingen, 2017.

Governo do Rio de Janeiro. Plano diretor de transporte urbano da região metropolitana do Rio de Janeiro, Rio de Janeiro: Governo do Rio de Janeiro, 2013.

HARVEY, D. The Right to the City. International journal of urban and regional research, 27(4), 2003. p. 939-941.

. The right to the city. New Left Review, v. 53, 2008. p. 23-40.

. Rebel cities - from the right to the city to the urban revolution (E-book). London:

Verso, 2012.

LEFEBVRE, H. The production of space. Oxford: Blackwell Publishing, 1991. 
Cidade para Viver ou Trabalhar? Contradições da Distribuição de Atividades, Transporte... 1995. The right to the city. Cambridge: Blackwell, 1995.

A evolução urbana. Belo Horizonte: UFMG, 2008.

MAY, T.; PERRY, B. The future of urban sociology. Sociology, 39(2), 2005. p. 343-370.

MOLOTCH, H. Review: the space of Lefebvre. Theory and Society, 22(6), 1993. p. 887-895.

MPRJ, 2017. MPRJ em mapas. [Online] Disponível em: http://apps.mprj.mp.br/sistema/ mpmapas/inloco.html\#/plataforma. Acesso em 3 de junho de 2017.

Prefeitura do Rio de Janeiro. Lei Complementar n. 111 de 1 de fevereiro de 2011, Rio de Janeiro: Prefeitura do Rio de Janeiro, 2011.

2014. Armazém de dados. [Online] Disponível em: http://www.armazemdedados.rio.rj.gov.br/. Acesso em 3 de junho de 2017.

2017. Rede de transporte 2017. [Online] Disponível em: http://www.rio.rj.gov. br/web/pmus/mapa-da-rede-de-transportes. Acesso em 3 de junho de 2017.

SANTOS, M. A natureza do espaço: técnica e tempo, razão e emoção. São Paulo: Edusp, 2002.

SCOTT, A. J.; STORPER, M. The nature of cities: the scope and limits of urban theories. International Journal of Urban and Regional Research, 2014. p. 1-16.

SOJA, E., MORALES, R.; WOLFF, G. Urban restructuring: an analysis of social and spatial change in Los Angeles. Economic Geography, 59(2), 1983. p. 195-230.

VASCONCELLOS, E. A. Sociological and political approach to transport (Ebook). In: Urban Transport environment and equity: the case for developing countries (Ebook). s.l.:Routledge, 2014. p. 1-38.

Urban transport environment and equity: the case for developing countries (eBook). s.I.: Routledge, 2014.

WALTON, J. Urban sociology: the contribution and limits of political economy. Annual Review of Sociology, 1993. v. 19. p. 301-320.

Recebido em: 18/10/2017 Aceito em: 14/11/2017 